\title{
Performance Evaluation on Transmission Tower-Line System with Passive Friction Dampers Subjected to Wind Excitations
}

\author{
Bo Chen, ${ }^{1}$ Xiang Xiao, ${ }^{2}$ Peng-yun $\mathrm{Li}^{3}$ and Wan-li Zhong ${ }^{3}$ \\ ${ }^{1}$ Key Laboratory of Roadway Bridge and Structural Engineering, Wuhan University of Technology, Mail Box No. 219, \\ No. 122, Luoshi Road, Wuhan 430070, China \\ ${ }^{2}$ School of Transportation, Wuhan University of Technology, Wuhan 430070, China \\ ${ }^{3}$ Guangdong Power Grid Corporation Co. Ltd., Guangzhou 510080, China \\ Correspondence should be addressed to Bo Chen; cbsteven@163.com
}

Received 30 August 2014; Accepted 21 October 2014

Academic Editor: Ting-Hua Yi

Copyright (C) 2015 Bo Chen et al. This is an open access article distributed under the Creative Commons Attribution License, which permits unrestricted use, distribution, and reproduction in any medium, provided the original work is properly cited.

\begin{abstract}
The vibration control and performance evaluation on a transmission-tower line system by using friction dampers subjected to wind excitations are carried out in this study. The three-dimensional finite element (FE) model of a transmission tower is firstly constructed. A two-dimensional lumped mass model of a transmission tower is developed for dynamic analysis. The analytical model of transmission tower-line system is proposed by taking the dynamic interaction between the tower and the transmission lines into consideration. The mechanical model of passive friction damper is presented by involving the effects of damper axial stiffness. The equation of motion of the transmission tower-line system incorporated with the friction dampers disturbed by wind excitations is established. A real transmission tower-line system is taken as an example to examine the feasibility and reliability of the proposed control approach. An extensive parameter study is carried out to find the optimal parameters of friction damper and to assess the effects of slipping force axial stiffness and hysteresis loop on control performance. The work on an example structure indicates that the application of friction dampers with optimal parameters could significantly reduce wind-induced responses of the transmission tower-line system.
\end{abstract}

\section{Introduction}

Overhead transmission tower-line system is a typical kind of electrical power infrastructures widely used throughout the world for energy supplying. To be a high-rise structure, the transmission tower-line system is prone to strong wind excitations due to its small damping [1-3]. The excessive vibration of a transmission tower-line system due to strong wind loadings may induce the structural damage or failure associated with the events such as member fracture, member buckling, and tower collapse. The failure of the towers under wind loading has been frequently reported across the world [4-6]. To mitigate the dynamic responses of the transmission tower-line system, many theoretical, experimental, and field measurement investigations have been carried out during the past two decades [7-9]. The current approaches and techniques used for performance evaluation and control can be classified into two major categories. The first one is the conventional approach developed by increasing the structural stiffness while accepting an intensive level of wind excitations. The other one is an alternative approach to prevent structural failure by installing vibration control devices.

Current studies on the vibration control of transmission tower-line systems focus on the application of dynamic absorbers and energy-dissipating dampers [10]. A typical device commonly utilized for vibration mitigation of the high-rise structures is the tuned mass damper (TMD). The application of the TMD can reduce the structural dynamic responses to some extent while several additional masses should be installed on top of a transmission tower which requires the occupancy of the structural space. In addition, due to the passive nature of TMD, it can only suppress the vibration of tuned mode shapes instead of the global dynamic responses. Therefore, the control performance of the TMD on transmission tower-line system is limited. To 
overcome the shortcoming of the dynamic absorbers, many energy-dissipating dampers have been developed recently as an alternative approach for dynamic mitigation of transmission tower-line system. Up to now, the vibration control of transmission tower-line system subjected to dynamic excitations has been investigated rarely [11, 12]. Chen et al. proposed a new method for the wind-resistant design of the transmission tower-line system by using viscoelastic dampers [13]. Chen et al. also proposed a novel approach for the windinduced semiactive vibration control of transmission towerline system by using magnetorheological (MR) dampers. However, it is widely reported that the performance of the viscoelastic dampers can be substantially weakened under the harsh environment, which cannot be avoided for the transmission tower-line system in the open air [10, 14]. The configuration and fabrication of the semiactive control devices, such as MR damper, are quite complicated and the requirement in the additional energy supply during the vibration control process is unrealistic while accepting strong excitations. Therefore, the passive friction dampers with a simple configuration and excellent environmental adaptability can be adopted to suppress the wind-induced responses of the transmission tower-line system. The friction damper is a typical energy-dissipating device utilized in the structural response control application and it can be manufactured as an axial member to replace common structural members of a tower without requiring the additional space occupancy.

To this end, the vibration control and performance evaluation on a transmission tower-line system with passive friction dampers subjected to wind loading is actively carried out in this study. The three-dimensional finite element model of a transmission tower is firstly constructed and then a twodimensional lumped mass model is also developed. The analytical model of transmission tower-line system is proposed by taking the dynamic interaction between the tower and the transmission lines into consideration. The mechanical model of the friction damper is presented by considering the effects of damper axial stiffness. The equation of motion of the transmission tower-line system incorporated with the friction dampers disturbed by wind excitations is established for both the in-plane and out-of-plane vibration, respectively. A real transmission tower-line system constructed in southern China is taken as an example to examine the feasibility and reliability of the proposed control approach. In addition, a parametric study is conducted in detail in order to examine the effects of the slipping force, the axial stiffness, and the hysteresis loop on the control performance. The made observations indicate that the passive friction dampers can be utilized to suppress the wind-induced vibration control of the transmission tower-line system due to its satisfactory energydissipating capacity if the damper parameters are optimally determined.

\section{Model of Transmission Tower-Line System}

2.1. Model of Transmission Tower. To be a typical truss tower constructed by using steel members, a transmission tower can

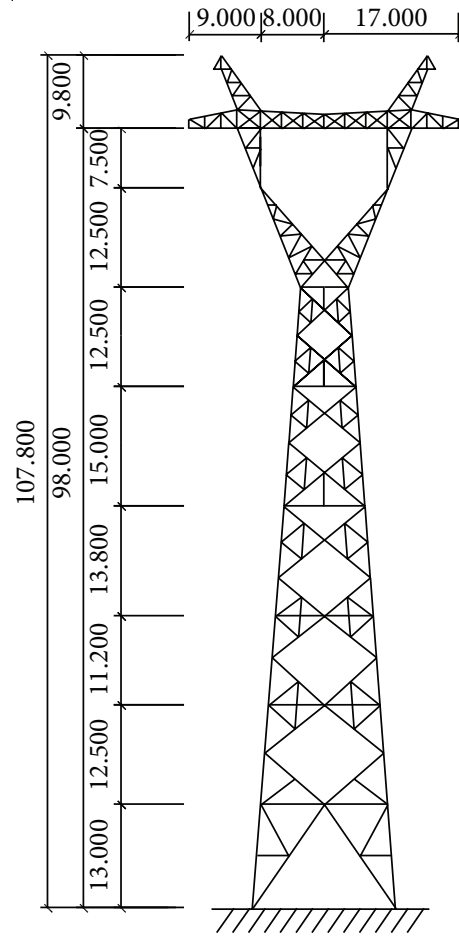

(a) Three-dimensional FE model

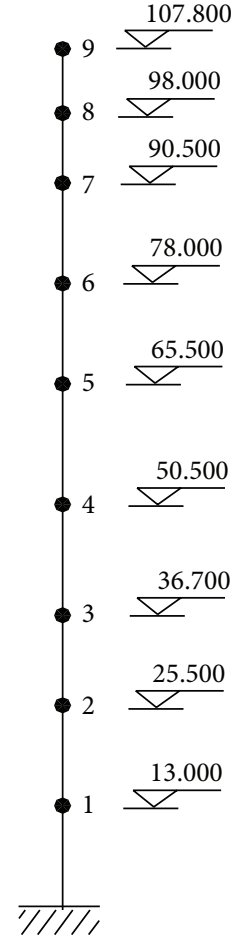

(b) Lumped mass model
FIgURE 1: Analytical model of a transmission tower.

be commonly modelled by using the beam elements based on the finite element (FE) method $[15,16]$. The mass matrix of a single member of the tower can be expressed as

$$
\mathbf{M}^{(i)}=\mathbf{T}_{e}^{(i) T} \mathbf{M}_{e}^{(i)} \mathbf{T}_{e}^{(i)}
$$

in which $\mathbf{M}^{(i)}$ and $\mathbf{M}_{e}^{(i)}$ denote the element mass matrix of the $i$ th element in the global coordinate system (GCS) and the local coordinate system (LCS), respectively; $\mathbf{T}_{e}^{(i)}$ denotes the coordinate transformation matrix of the $i$ th element.

Similarly, the element stiffness matrix of the $i$ th element in the GCS $\mathbf{K}^{(i)}$ can be expressed as the multiple of the element stiffness matrix $\mathbf{K}_{e}^{(i)}$ in the LCS with the coordinate transformation matrix $\mathbf{T}_{e}^{(i)}$

$$
\mathbf{K}^{(i)}=\mathbf{T}_{e}^{(i) T} \mathbf{K}_{e}^{(i)} \mathbf{T}_{e}^{(i)} .
$$

The global mass matrix $\mathbf{M}_{t}$ and the stiffness matrix $\mathbf{K}_{t}$ of a transmission tower can be expressed as follows:

$$
\begin{aligned}
\mathbf{M}_{t} & =\sum_{i=1}^{n e} \mathbf{T}^{(i) T} \mathbf{M}^{(i)} \mathbf{T}^{(i)} \\
\mathbf{K}_{t} & =\sum_{i=1}^{n e} \mathbf{T}^{(i) T} \mathbf{K}^{(i)} \mathbf{T}^{(i)},
\end{aligned}
$$

where $n e$ is the number of elements of the tower model; $\mathbf{T}^{(i)}$ is the freedom transform matrix from the LCS to the GCS. 


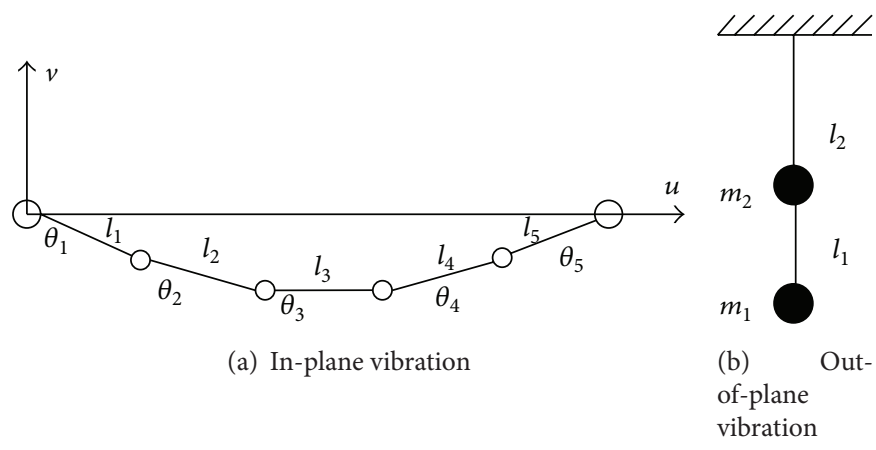

FIGURE 2: MDOF elastic model of a transmission line.

The three-dimensional (3D) FE model of a transmission tower is displayed in Figure 1(a). If the configuration of a transmission tower is quite complicated due to a great number of structural members and components, a remarkable number of the degree of freedoms (DOFs) of the tower can be expected. Therefore, it is impractical for the dynamic response computation and the investigation on the control performance because the numerical step-by-step integration in the time domain will be very time-consuming. In addition, the dynamic excitation on the tower such as wind loads can commonly be modeled as a stationary or nonstationary stochastic process in time and nonhomogeneous in space. The simulation of dynamic loading of a complicate threedimensional FE model of a transmission tower requires enormous computation efforts. From the practical viewpoint, a simple analytical model of the transmission tower with limited DOFs is more reasonable for the investigation on structural dynamic responses and the parametric study. In this regard, a two-dimensional (2D) lumped mass model is commonly used in practice to examine the dynamic responses of a complicated transmission tower.

When a 3D FE dynamic model of a transmission tower is reduced to a $2 \mathrm{D}$ lumped mass model, some assumptions are commonly adopted. As far as the 2D lumped model is concerned, the masses of the transmission tower, including the masses of all structural components and all nonstructural components, are first concentrated at several floors only. The average of the displacements of all nodes at a certain floor is defined as the nominal displacement of that floor in that direction. Then, the number of dynamic degrees of freedom of the $2 \mathrm{D}$ lumped mass model is the number of the selected floors. The mass matrix $\mathbf{M}$ of the $2 \mathrm{D}$ lumped mass model is a diagonal matrix which can be expressed as

$$
\mathbf{M}=\left[\begin{array}{llllll}
m_{1} & & & & & \\
& m_{2} & & & & \\
& & \ddots & & & \\
& & & m_{j} & & \\
& & & & \ddots & \\
& & & & & m_{n m}
\end{array}\right] \quad(j=1,2, \ldots, n m)
$$

in which $m_{j}$ denotes the mass of the $j$ th floor; $n m$ is the floor number of the transmission tower. The stiffness matrix $\mathbf{K}$ of the $2 \mathrm{D}$ lumped mass model can be obtained based on the $3 \mathrm{D}$
FE model of the transmission tower by taking the following steps.

(1) Apply the same horizontal force at each node at the $i$ th floor of the 3D model such that the sum of all forces equals 1.

(2) Determine the horizontal displacement of each node at the $j$ th floor. Define the nominal displacement of the $j$ th floor to have the flexibility coefficient $\delta_{j i}(i, j=1,2, \ldots, n m)$.

(3) Form the flexibility matrix $\Psi$ and inverse the flexibility matrix to obtain the $2 \mathrm{D}$ stiffness matrix $\mathbf{K}$ of the transmission tower.

2.2. Model of Transmission Tower-Line System. The transmission line can be modeled as several lumped masses connected with many elastic elements $[17,18]$. The analytical models of a transmission line for in-plane/out-of-plane vibration with six lumped masses and five elastic elements are displayed in Figure 2. Regarding the in-plane vibration of the transmission line, the kinetic energy and the potential energy of a transmission line can be computed by using the generalized velocity and generalized displacement, respectively. The application of the Hamilton's variational principle can lead to the equation of motion of a transmission line [19]. The kinetic energy of the transmission line can be expressed based on the Lagrange formulation

$$
\begin{aligned}
T_{\text {line }} & =\sum_{i=1}^{4} \frac{1}{2} m_{i}\left(\dot{u}_{i}^{2}+\dot{v}_{i}^{2}\right) \\
& =T_{\text {line }}\left(\dot{\xi}_{2}, \dot{\xi}_{3}, \dot{\xi}_{4}, \delta \dot{l}_{1}, \delta \dot{l}_{2}, \delta \dot{l}_{3}, \delta \dot{l}_{4}, \delta \dot{l}_{5}\right),
\end{aligned}
$$

where $\xi$ and $\delta$ are the generalized coordinates of a transmission line related to the difference of the angle $\theta$ and length $l$, respectively; $u_{i}$ and $v_{i}$ are the displacement of the $i$ th lumped mass in the horizontal and vertical direction, respectively.

Similarly, the potential energy of the transmission line is given by

$$
U_{\text {line }}=\sum_{i=1}^{4} m_{i} g v_{i}+\sum_{j=1}^{5} \frac{E A}{2}\left(\frac{\left(l_{j s}+\delta l_{j}\right)^{2}}{l_{j 0}}-\frac{l_{j s}^{2}}{l_{j 0}}\right),
$$


where $E$ and $A$ are Young's modulus and the cross section area of a transmission line; $l_{j 0}$ is the length of the $j$ th element; $l_{j s}$ is the length of the $j$ th element after deformation. The mass matrix $\mathbf{M}_{l}^{\text {in }}$ can be determined by computing the partial differential of the kinetic energy to the generalized velocity. Similarly, the stiffness matrix $\mathbf{K}_{l}^{\text {in }}$ can be determined by computing the partial differential of the potential energy to the generalized displacement.

Figure 2(b) displays the analytical model of transmission line for the out-of-plane vibration. The transmission line can be taken as a hanging line with several lumped masses. The mass matrix $\mathbf{M}_{l}^{\text {out }}$ and stiffness matrix $\mathbf{K}_{l}^{\text {out }}$ of the transmission line can be expressed as

$$
\begin{gathered}
\mathbf{M}_{l}^{\text {out }}=\left[\begin{array}{ll}
m_{1} & \\
& m_{2}
\end{array}\right] \\
\mathbf{K}_{l}^{\text {out }}=\left[\begin{array}{cc}
\frac{m_{1} g}{l_{1}} & -\frac{m_{1} g}{l_{1}} \\
-\frac{m_{1} g}{l_{1}} & \frac{m_{1} g}{l_{1}}+\frac{\left(m_{1}+m_{2}\right) g}{l_{2}}
\end{array}\right] .
\end{gathered}
$$

The kinetic energy of the tower-line system for the in-plane vibration is given by

$$
T=\sum_{i=1}^{n l} T_{\text {line }}^{i}+\sum_{j=1}^{n t} T_{\text {tower }}^{j}
$$

in which $n l$ and $n t$ are the number of the transmission lines and towers of the transmission tower-line system, respectively. Similarly, the potential energy of the tower-line system is given by

$$
U=\sum_{i=1}^{n l} U_{\text {line }}^{i}+\sum_{j=1}^{n t} U_{\text {tower }}^{j} .
$$

By substituting (8) and (9) into the Lagrange equation, the mass matrix $\mathbf{M}^{\text {in }}$ and stiffness matrix $\mathbf{K}^{\text {in }}$ of a transmission tower-line system for the in-plane vibration can be determined by computing the partial differential of the kinetic energy $T$ and potential energy $U$ to generalize coordinates and its first time derivatives. Similarly, the mass matrix $\mathbf{M}^{\text {out }}$ and stiffness matrix $\mathbf{K}^{\text {out }}$ of the transmission tower-line system for the out-of-plane vibration can be determined by consideration of the coupled effects induced by transmission lines [1].

\section{Model of Friction Damper}

Passive friction dampers are the devices utilizing the mechanism of the solid friction to achieve the energy dissipation. In reality, this concept has been successfully used by mechanical engineers to control the motion of machinery and automobiles. The passive friction damper can be designed with a specific optimum slip force under a particular external excitation (Figure 6). The development of friction damping devices was pioneered in the early 1980s, thereafter, a considerable progress in developing a number of energydissipating devices in the structural vibration control [2023]. The configuration of a typical passive friction damper

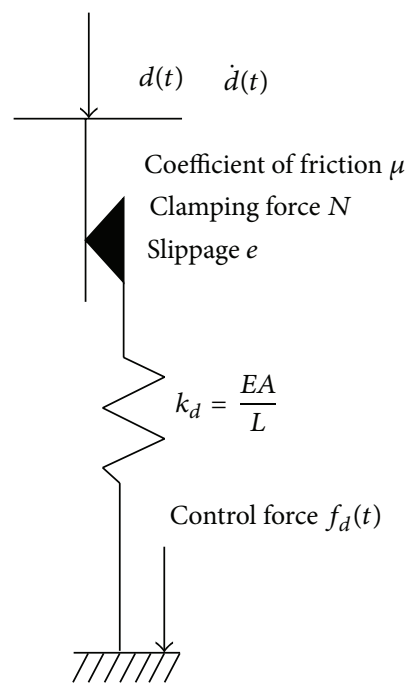

FIGURE 3: Configuration of passive friction damper.

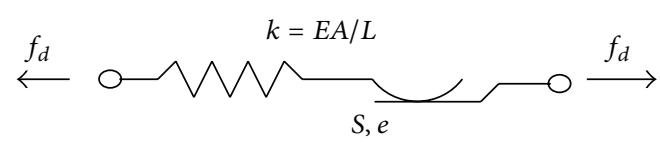

FIGURE 4: Mechanical model of friction damper.

is displayed in Figure 3. In the early stage, the control force of the friction damper is expressed as the product of the clamping force $N$ and the coefficient of friction $\mu$ without considering the effects of the damper axial stiffness $k_{d}$. However, it is found that the performance of the friction damper is tightly related to the axial stiffness of the damper and many mechanical models with the elastic axial member are developed based on the experimental observations.

Commonly, the control force of a friction damper is transferred to the structure through an elastic axial member. Thus, the model of a friction damper should include the stiffness of the elastic member as shown in Figure 4. In Figure $4, S$ denotes the slip force of the $i$ th friction damper which equals the product of the clamping force $N$ and the friction coefficient $\mu$; $e$ denotes the slip deformation of the $i$ th friction damper and it is equal to zero initially: $E$ denotes Young's modulus of the damper; $A$ is the cross section area of the $i$ th elastic member; and $L$ is the length of the $i$ th member. The control force of the $i$ th friction damper can be expressed as

$$
u_{i}=u(k, e, S)
$$

where $k$ denotes the axial stiffness of a passive friction damper.

The clamping force of a passive friction damper is set in advance and its friction force is constant during the slipping process. The condition and control force of the $i$ th passive friction damper can be determined using the following rules. 


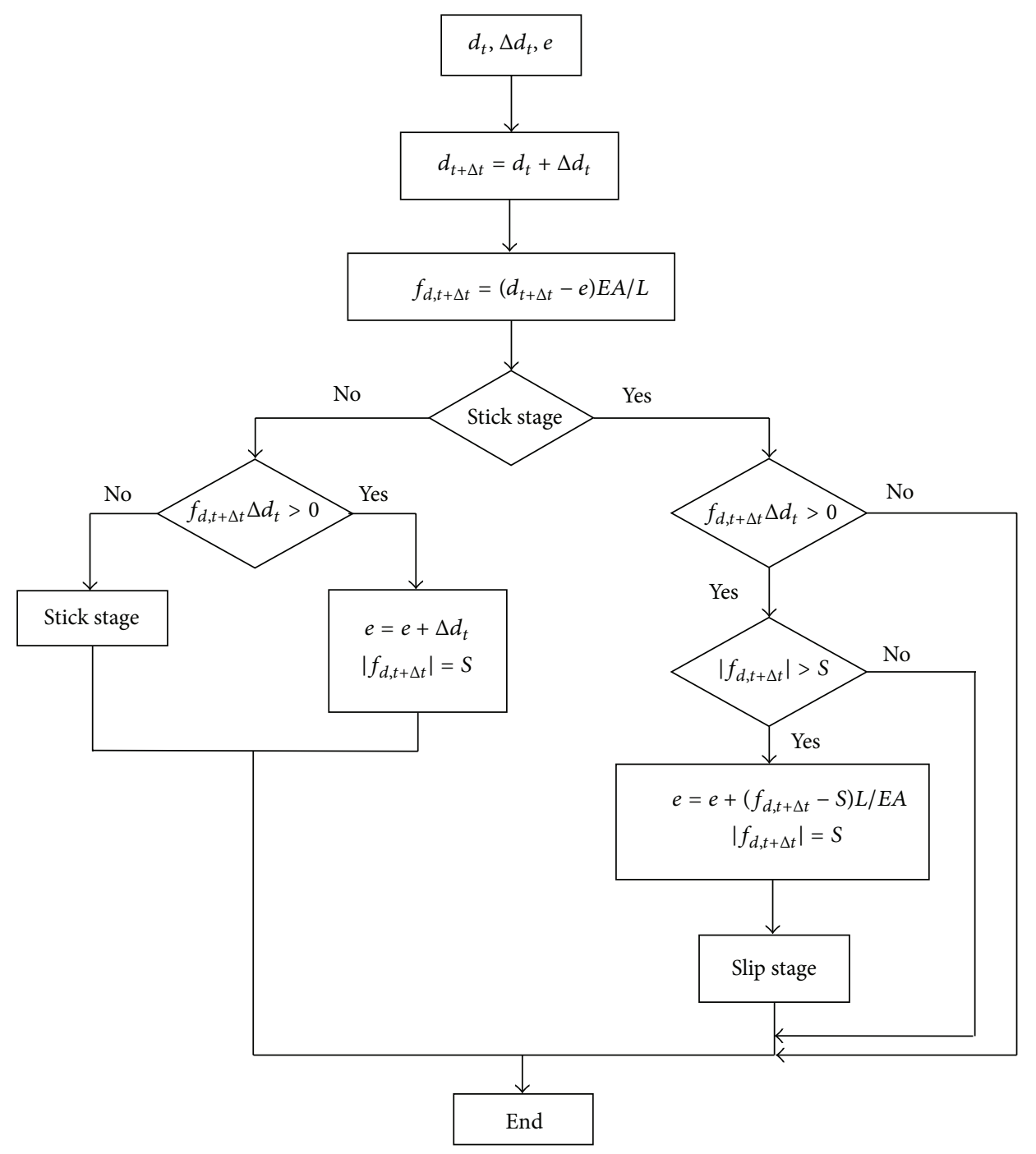

FIGURE 5: Force flow chart of passive damper.

(1) If the friction damper has no slippage, then

$$
\begin{gathered}
f_{d}^{i}=\left(d_{i}-e_{i}\right) \frac{E A_{i}}{L_{i}} \\
\dot{e}_{i}=0 .
\end{gathered}
$$

(2) If the friction damper has a slippage

$$
\begin{gathered}
\left|f_{d}^{i}\right|=S_{i}=f_{d}^{i} N_{i} \operatorname{sgn}\left(\dot{d}_{i}\right) \\
\dot{e}_{i}=\dot{d}_{i},
\end{gathered}
$$

where $d_{i}$ and $\dot{d}_{i}$ are relative displacement and velocity between the two ends of the $i$ th friction damper, respectively. Furthermore, if the relative displacement increment of the two ends of the $i$ th friction element $\Delta d_{i}$ is larger than zero, the control force is tensile. Otherwise, the control force is compressive.
(3) If the control force $u_{i}$ is of different sign with the relative displacement increment $\Delta d_{i}$, the friction damper is in the stick stage. Under this circumstance, the resistant force and slippage of friction damper should be determined following (11).

The flow chart for judging the slipping condition and the control force of a friction damper is indicated in Figure 5.

\section{Equation of Motion of Transmission Tower-Line System}

The wind loading acting on a transmission tower-line system can be simulated with the aids of the spectral representation approach by assuming the wind excitations to be a stationary stochastic process. The stochastic wind fields 


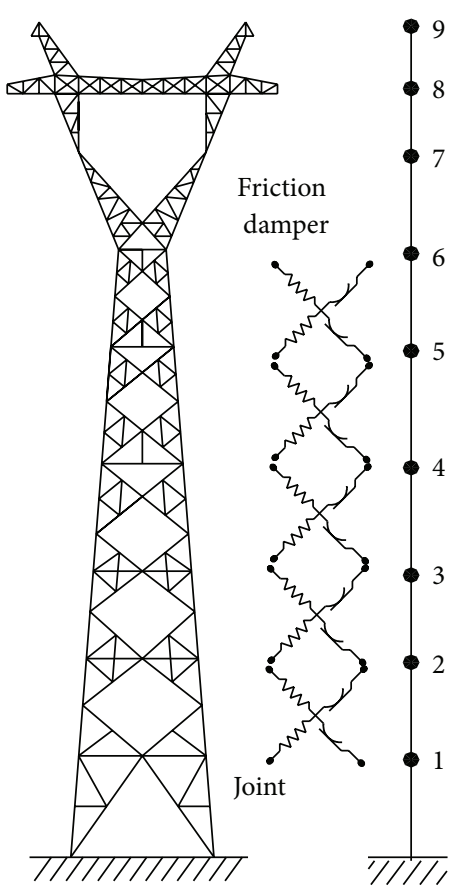

FIgURE 6: Installation scheme of friction damper.

$p_{j}^{0}(t), j=1,2, \ldots, n m$, can be simulated by using the following series [24]:

$$
\begin{gathered}
p_{j}(t) \\
=2 \sqrt{\Delta \omega} \sum_{m=1}^{j} \sum_{l=1}^{N}\left|H_{j m}\left(\omega_{m l}\right)\right| \cos \left(\omega_{m l} t-\theta_{j m}\left(\omega_{m l}\right)+\varphi_{m l}\right) \\
\Delta \omega=\frac{\omega_{\mathrm{up}}}{N},
\end{gathered}
$$

where $N$ is a sufficiently large number; $\Delta \omega$ is the frequency increment; $\omega_{\text {up }}$ is the upper cutoff frequency with the condition that when $\omega>\omega_{\text {up }}$, the value of the cross spectral density matrix $\mathbf{S}^{0}(\omega)$ is trivial; $\phi_{m l}$ represents a sequence of independent random phase angles, uniformly distributed over the interval $[0,2 \pi] ; H_{j m}(\omega)$ is a typical element of matrix $\mathbf{H}(\omega)$, which is defined with the Cholesky decomposition of the $\mathbf{S}^{0}(\omega) ; \theta_{j m}(\omega)$ is the complex angle of $H_{j m}(\omega)$.

The equation of motion of the transmission tower-line system for in-plane vibration subjected to wind loading is given by

$$
\mathbf{M}^{\text {in }} \ddot{\mathbf{x}}^{\text {in }}(t)+\mathbf{C}^{\text {in }} \dot{\mathbf{x}}^{\text {in }}(t)+\mathbf{K}^{\text {in }} \mathbf{x}^{\text {in }}(t)=\mathbf{P}^{\text {in }}(t),
$$

where $\mathbf{x}^{\text {in }}(t), \dot{\mathbf{x}}^{\text {in }}(t)$, and $\ddot{\mathbf{x}}^{\text {in }}(t)$ are the displacement, velocity, and acceleration responses for the in-plane vibration, respectively; $\mathbf{M}^{\text {in }}, \mathbf{C}^{\text {in }}$, and $\mathbf{K}^{\text {in }}$ are mass and damping and stiffness matrices of the tower-line system for the in-plane vibration, respectively; $\mathbf{P}^{\mathrm{in}}(t)$ is the wind loading vector for the in-plane
TABLE 1: Parameters of friction damper.

\begin{tabular}{lcc}
\hline $\begin{array}{l}\text { Young's modulus } \\
(\mathrm{N} / \mathrm{m})\end{array}$ & $\begin{array}{c}\text { Cross section area } \\
\left(\mathrm{m}^{2}\right)\end{array}$ & $\begin{array}{c}\text { Maximum slippage } \\
(\mathrm{m})\end{array}$ \\
\hline $2.06 \times 10^{11}$ & $7.5 \times 10^{-4}$ & 0.08 \\
\hline
\end{tabular}

vibration. Similarly, the equation of motion for the out-ofplane vibration can be expressed as

$$
\mathbf{M}^{\text {out }} \ddot{\mathbf{x}}^{\text {out }}(t)+\mathbf{C}^{\text {out }} \dot{\mathbf{x}}^{\text {out }}(t)+\mathbf{K}^{\text {out }} \mathbf{x}^{\text {out }}(t)=\mathbf{P}^{\text {out }}(t) \text {. }
$$

The meanings of the symbols in (15) are similar to those in (14).

The equations of motion of the transmission tower-line system with friction dampers for both the in-plane and outof-plane vibration can be expressed as follows:

$$
\begin{gathered}
\mathbf{M}^{\text {in }} \ddot{\mathbf{x}}^{\text {in }}(t)+\mathbf{C}^{\text {in }} \dot{\mathbf{x}}^{\text {in }}(t)+\mathbf{K} \mathbf{x}^{\text {in }}(t)=\mathbf{P}^{\text {in }}(t)+\mathbf{H}^{\text {in }} \mathbf{f}_{d}^{\text {in }}(t) \\
\mathbf{M}^{\text {out }} \ddot{\mathbf{x}}^{\text {out }}(t)+\mathbf{C}^{\text {out }} \dot{\mathbf{x}}^{\text {out }}(t)+\mathbf{K} \mathbf{x}^{\text {out }}(t) \\
=\mathbf{P}^{\text {out }}(t)+\mathbf{H}^{\text {out }} \mathbf{f}_{d}^{\text {out }}(t),
\end{gathered}
$$

where $\mathbf{f}_{d}^{\text {in }}(t)$ and $\mathbf{f}_{d}^{\text {out }}(t)$ are the control forces of friction dampers for in-plane vibration and out-of-plane vibration, respectively; $\mathbf{H}^{\text {in }}$ and $\mathbf{H}^{\text {out }}$ are the influence matrix for the control forces for the in-plane vibration and out-of-plane vibration, respectively.

\section{Case Study}

To examine the feasibility of the proposed control approach based on friction dampers, a real transmission tower-line system constructed in China is taken as the example structure to investigate the control performance. The tower has a height of $107.8 \mathrm{~m}$ and the span of the transmission line is $400 \mathrm{~m}$ as shown in Figure 1 . The axial rigidity EA of the transmission line is $4.8 \times 10^{7} \mathrm{~N}$ and the weight per meter of the transmission line is $1.394 \mathrm{kN} / \mathrm{m}$. A $3 \mathrm{D}$ model is constructed based on the FE method and a two-dimensional lumped mass model is also developed. The wind excitations are numerically simulated by using the spectral representation method. The Rayleigh damping assumption is adopted to construct the structural damping matrix. The damping ratios in the first two modes of vibration of the tower are assumed to be 0.02 . Twenty passive friction dampers are evenly distributed along the main body of the tower with ten dampers placed in the in-plane direction and the other ten dampers placed in the out-of plane direction. Table 1 lists the physical parameters of the passive friction damper adopted in this study for the wind-induced vibration mitigation.

The comparison between the maximum responses without/with friction dampers is carried out for both the inplane and out-of-plane vibration, respectively. Four scenarios of slipping forces of the friction dampers are selected for the assessment on the control performance, namely, $20 \mathrm{kN}$, $40 \mathrm{kN}, 60 \mathrm{kN}$, and $80 \mathrm{kN}$. Displayed in Figure 7 are the maximum displacement, velocity, and acceleration responses of the transmission tower under different slipping forces of 


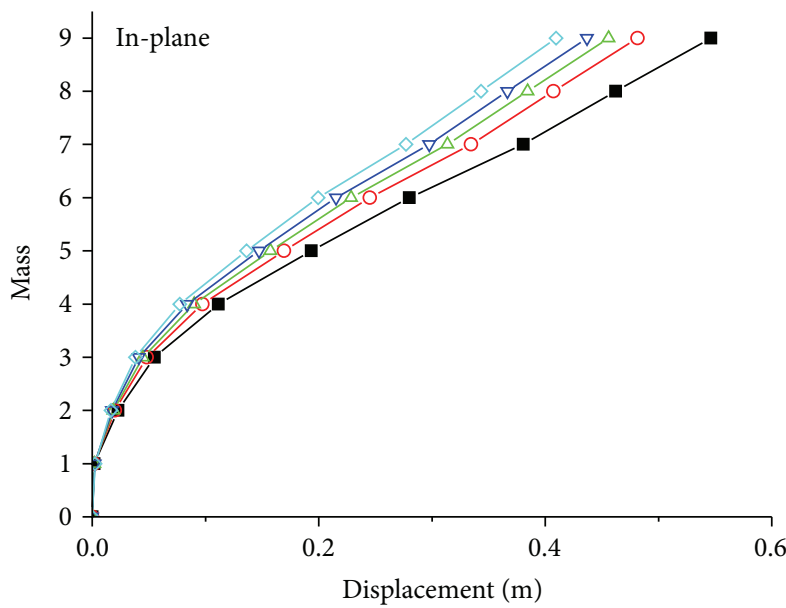

(a)

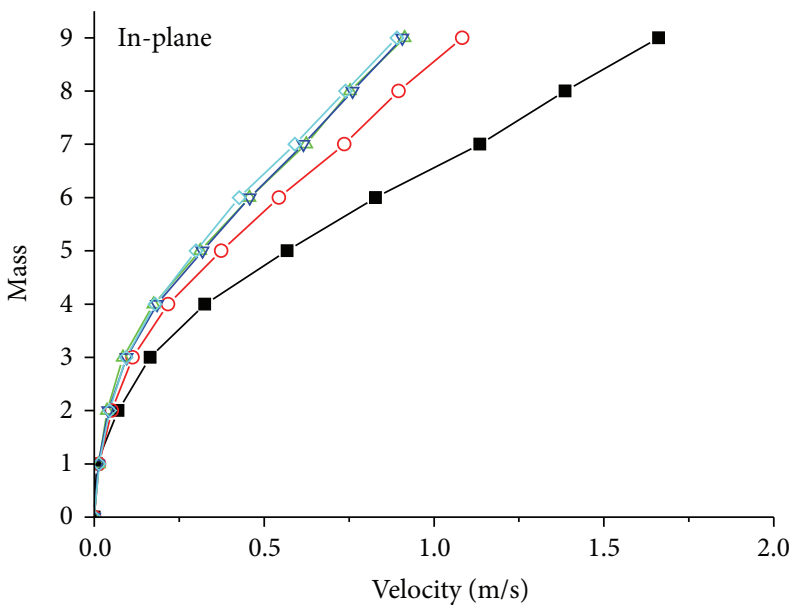

(c)

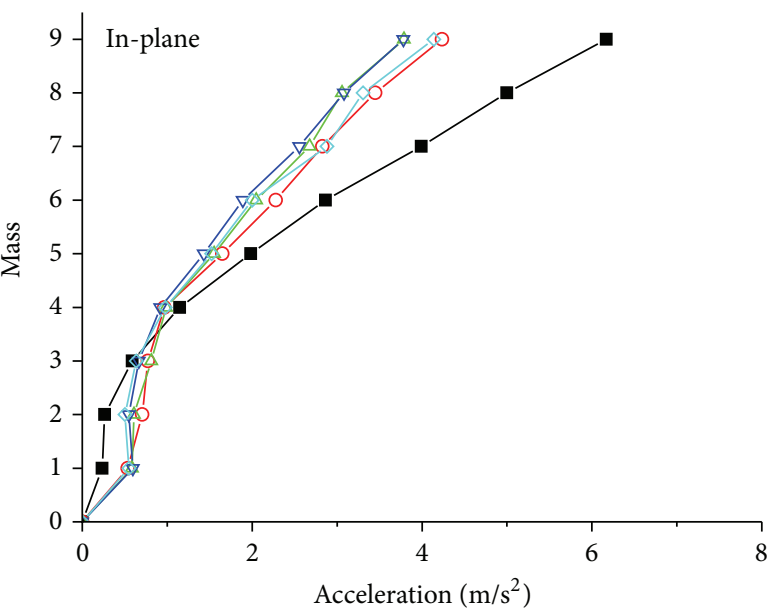

- - Original tower

$-0-f_{d}=20 \mathrm{kN}$

$-\nabla-f_{d}=60 \mathrm{kN}$

$$
\begin{aligned}
-\Delta-f_{d} & =40 \mathrm{kN} \\
-\diamond-f_{d} & =80 \mathrm{kN}
\end{aligned}
$$

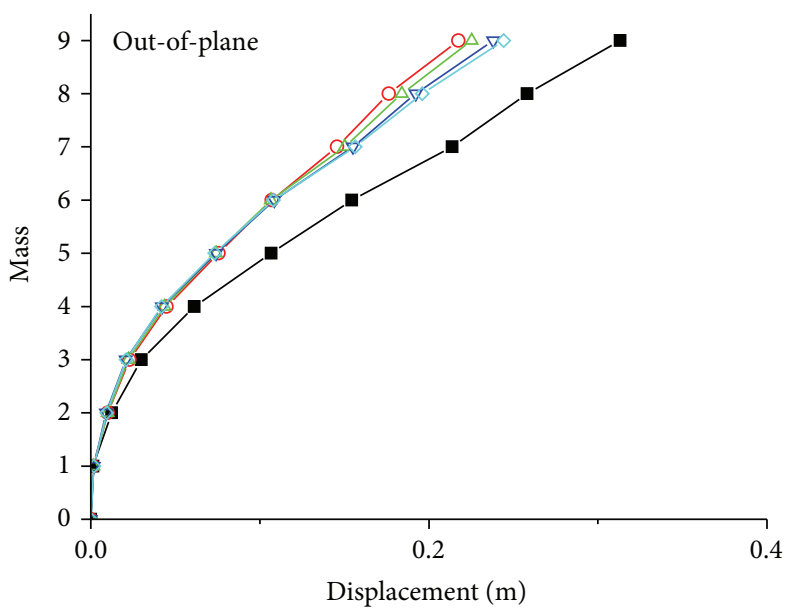

(b)

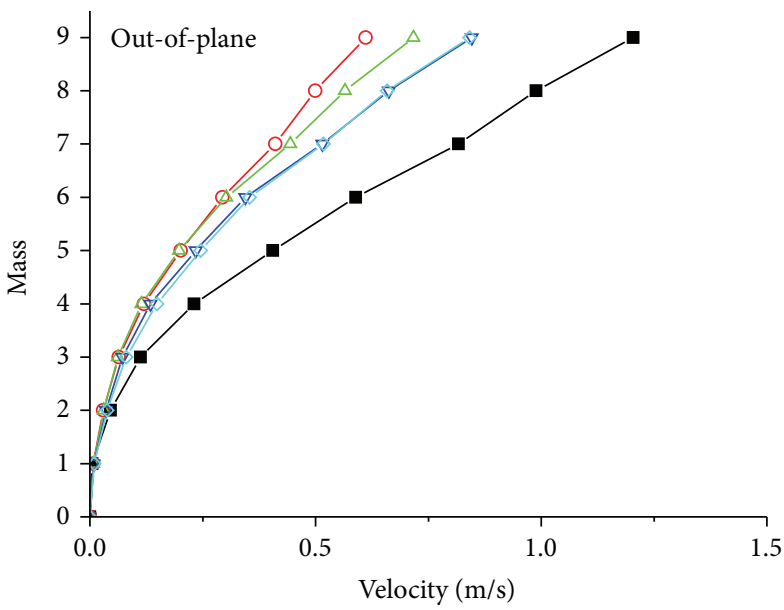

(d)

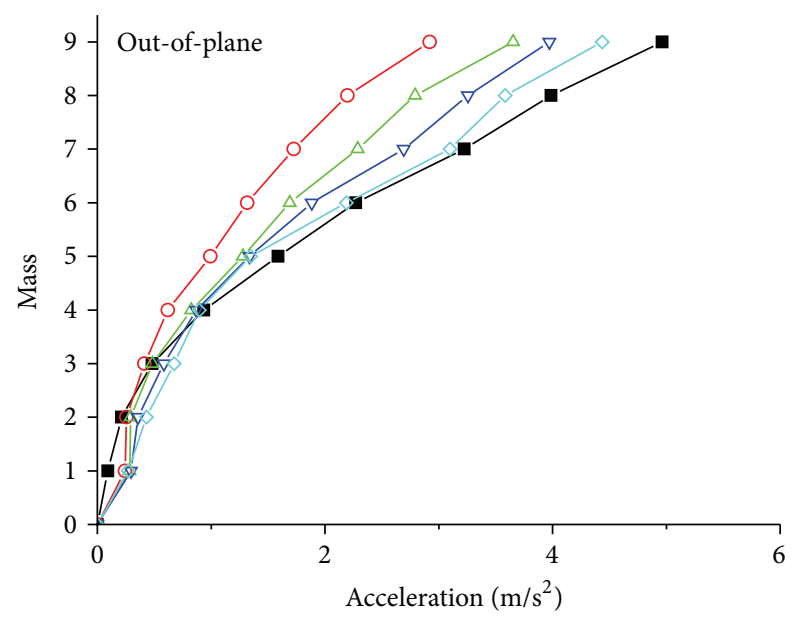

$\begin{array}{ll}-- \text { Original tower } & -\Delta-f_{d}=40 \mathrm{kN} \\ -0-f_{d}=20 \mathrm{kN} & -\diamond-f_{d}=80 \mathrm{kN} \\ -\nabla-f_{d}=60 \mathrm{kN} & \end{array}$

(f)

(e)

Figure 7: Maximum responses under different damper force. 


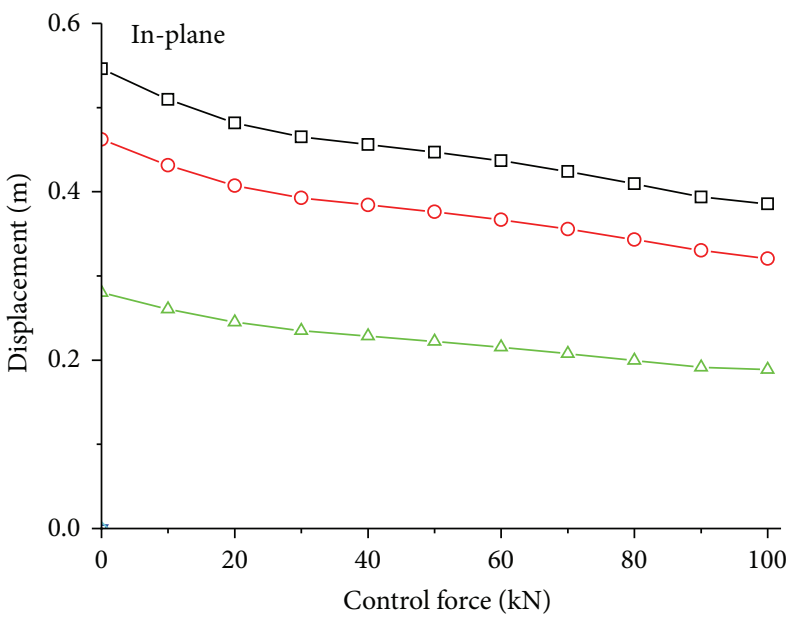

(a)

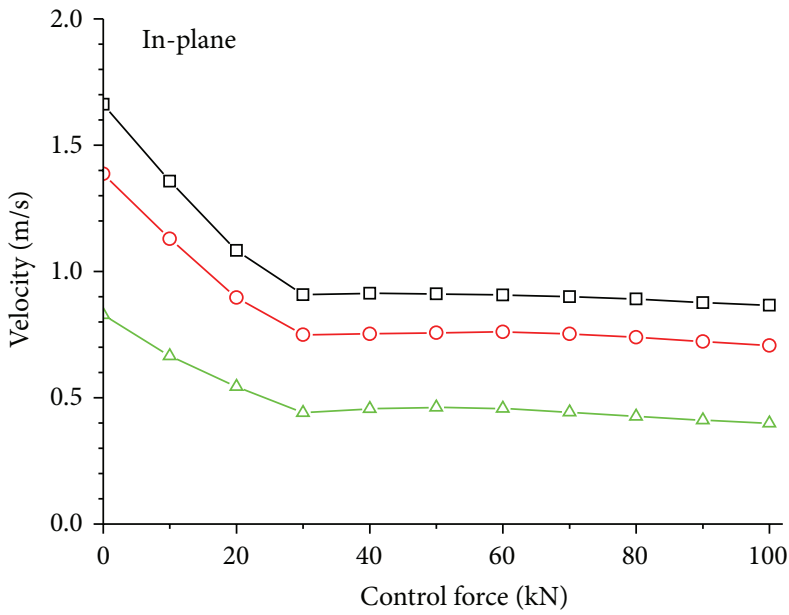

(c)

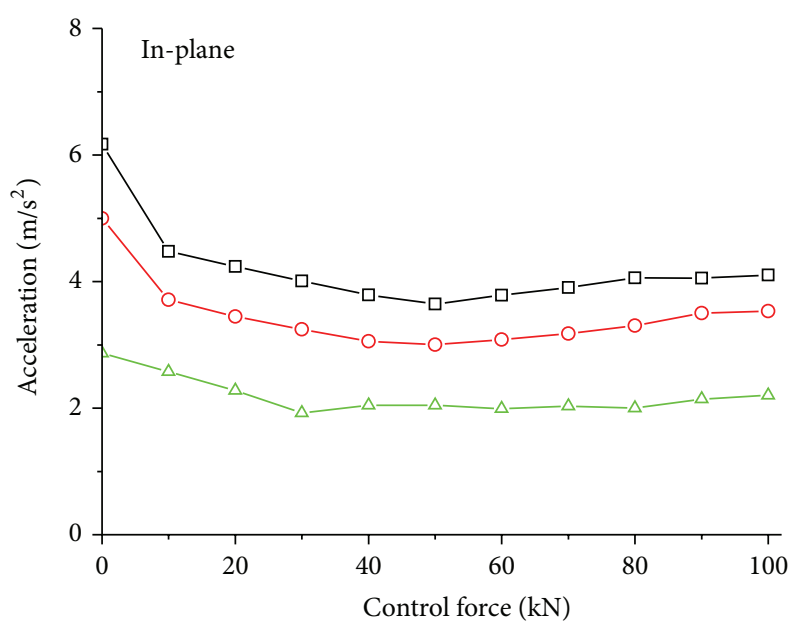

- - Mass number 9 (top)

-O- Mass number 8 (crossarm)

$-\Delta-$ Mass number 6

(e)

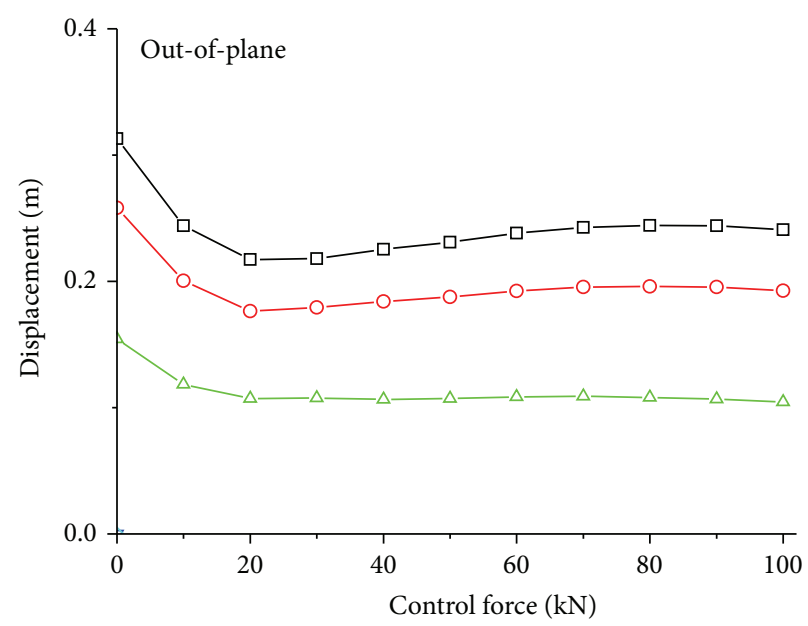

(b)

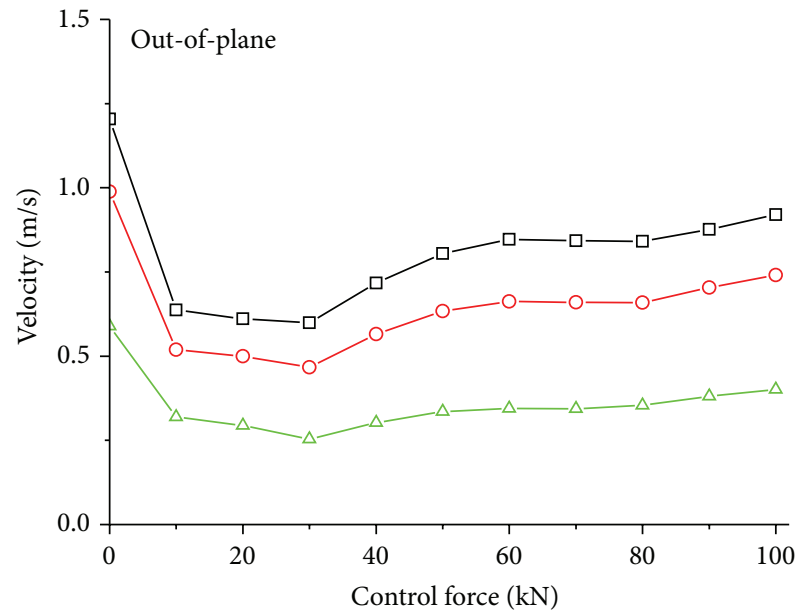

(d)

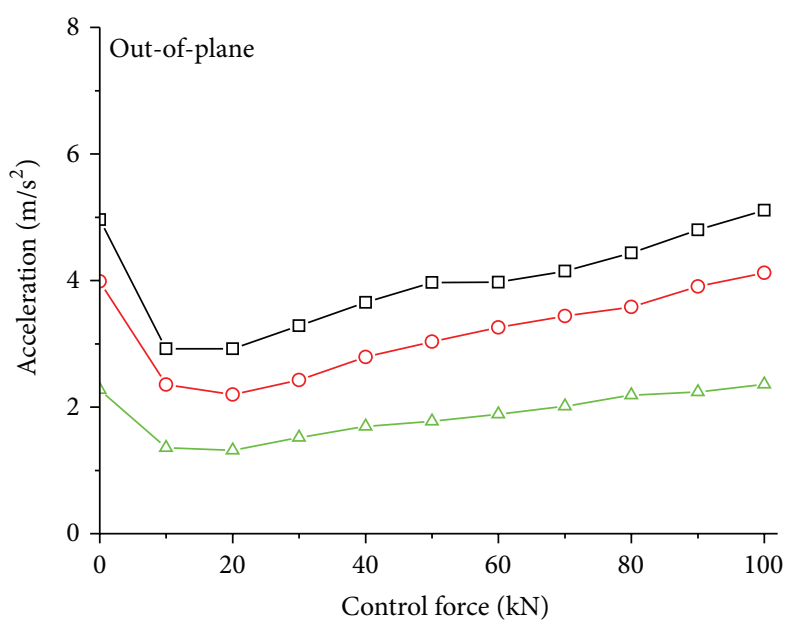

- - Mass number 9 (top)

-O- Mass number 8 (crossarm)

$-\Delta-$ Mass number 6

(f)

FIGURE 8: Variation of maximum responses with damper force. 
friction dampers in comparison with those without control. It is seen that the peak dynamic responses of the transmission tower can be remarkably reduced by incorporating the friction dampers. As far as the in-plane vibration is concerned, the peak displacement is gradually reduced with the increasing damper slipping force. The control scenario with $80 \mathrm{kN}$ presents the best control performance on the peak displacement responses despite the peak velocity and acceleration responses. Similar observations can be made from the results of the out-of-plane vibration. Therefore, the installation of the friction dampers can substantially suppress the wind-induced vibration of the transmission tower-line system for both the in-plane and out-of-plane vibration, respectively.

\section{Parametric Investigation}

6.1. Effects of Damper Force. The variations of peak responses of tower with respect to the slipping forces of the friction dampers are examined and displayed in Figure 8. Three typical positions are selected, namely, the tower top (mass number 9), the crossarm (mass number 8), and the top of the tower body (mass number 6). It is seen from Figure 8(a) that the peak displacement at the tower top, crossarm, and top of tower body gradually decreases when increasing the slipping forces of the friction dampers. Similar variation trends can be found for the out-of-plane vibration while the peak displacement slightly increases when the slipping force is larger than $20 \mathrm{kN}$. The variations of peak velocity displayed in Figures 8(b) and 8(c) present different characteristics compared to the peak displacement. The peak velocity and acceleration responses dramatically reduce at the beginning when the damper control forces are small. Then, the increment in the control forces of the friction damper has almost no efficacy on the peak velocity and acceleration responses for the in-plane vibration. For the out-of-plane vibration, the continuous increment in the control force may induce the slight increase of the peak velocity and acceleration responses. The same observations can be made from the dynamic responses of the other lumped masses such as the crossarm and the top of the tower body (mass number 6).

It is seen that no matter which tower mass is selected, there is an optimal value of control forces by which the best performance of the friction damper can be achieved. To compare the control performance of the three types of the dynamic responses of different places, one can find that there exists a small difference for the displacement, velocity, and acceleration responses. The optimal slipping forces of the friction dampers are about $40 \mathrm{kN}$ and $20 \mathrm{kN}$ for the inplane vibration and out-of-plane vibration, respectively. If the damper control force is increased after reaching the optimal value, the damper performance will deteriorate gradually. A possible explanation of such a phenomenon is that the unlimited increment in control forces may induce the stick of friction dampers when subjected to strong wind excitations. Under these circumstances, the friction dampers have no slippage and behave the same as a brace. The displacement responses may be reduced due to the stiffness increment of the tower while the velocity and acceleration responses cannot be improved because the damper has no slippage and energy dissipation. Similar results can be observed for other lumped masses. Therefore, the optimal slipping forces of the friction dampers are set as $40 \mathrm{kN}$ and $20 \mathrm{kN}$ for the in-plane vibration and out-of-plane vibration, respectively, in the parametric investigation.

6.2. Effects of Damper Stiffness. Figure 9 displays the variations of the peak displacement, velocity, and acceleration responses of the tower with respect to the brace stiffness of friction dampers. The stiffness coefficient of the damper is defined as

$$
\mathrm{SC}=\frac{k^{d}}{k_{0}^{d}}
$$

where $k^{d}$ denotes the damper stiffness used in the analysis, and $k_{0}^{d}$ denotes the stiffness parameter of a friction damper.

It is seen that the all the three types of dynamic responses for both the in-plane and out-of-plane vibration reduce rapidly when the stiffness coefficient of dampers increases from 0.0 to about 1.0. Afterwards, the peak responses vary slightly with increasing stiffness coefficient of dampers. When the stiffness coefficient exceeds 2.0, the damper stiffness has almost no effects on the structural peak responses. Similar results can be observed for other lumped masses as shown in Figure 9. As a result, the optimum stiffness coefficient of the friction dampers for the wind-induced response control of the example transmission tower is about 1.0. Further increase in the damper stiffness cannot substantially improve the control performance and leads to unnecessary cost increases.

6.3. Comparison on Hysteresis Loops. It is noted that the enclosed area of a hysteresis loop reflects the energy dissipated by the friction damper when subjected to dynamic excitations. Thus, the hysteresis loop with large enclosed area indicates the satisfactory control performance of the friction dampers. To this end, the present section contains the comparison on the force-displacement responses of the friction dampers with different stiffness coefficients. Figure 10 displays the hysteresis loops of a friction damper for the inplane vibration. The slipping forces of all the friction dampers for the in-plane vibration are set as $40 \mathrm{kN}$. In reality, the axial stiffness of the friction damper can be reflected by the slope of the hysteresis loop. It is seen from Figure 10(a) that if the axial stiffness is small, there will be a distinct axial deformation of the damper, which means that the damper slippage is small and the energy-dissipating of the damper is limited. To increase the damper axial stiffness, the friction damper is easy to slide and dissipate the vibrant energy. If the axial stiffness of a friction damper is large enough under the unchanged slipping force, its effects on the hysteresis loops keep constant and thus the improvement on control performance is minor. Displayed in Figure 11 is the comparison on hysteresis loops of friction dampers with different slipping forces and the same axial stiffness for the in-plane vibration. It is seen that the slope of the hysteresis loops of the damper decreases with the increasing 


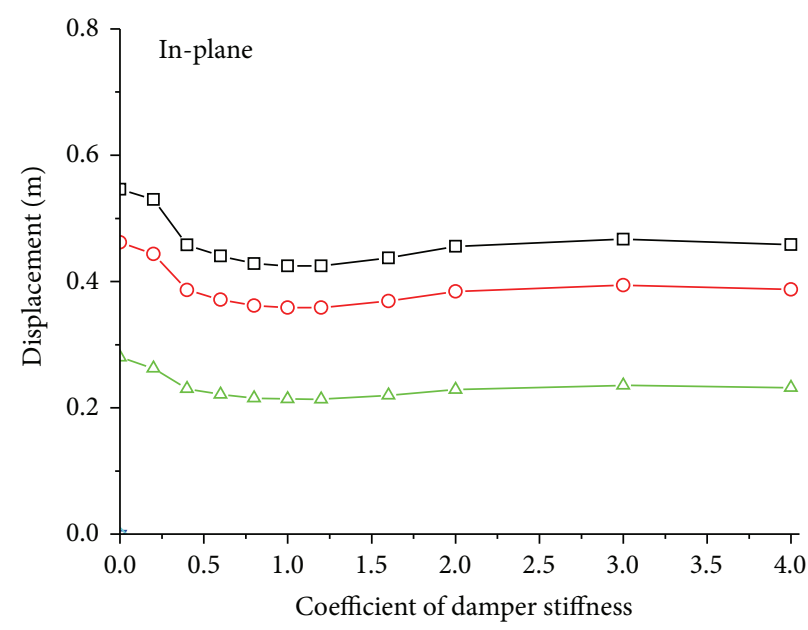

(a)

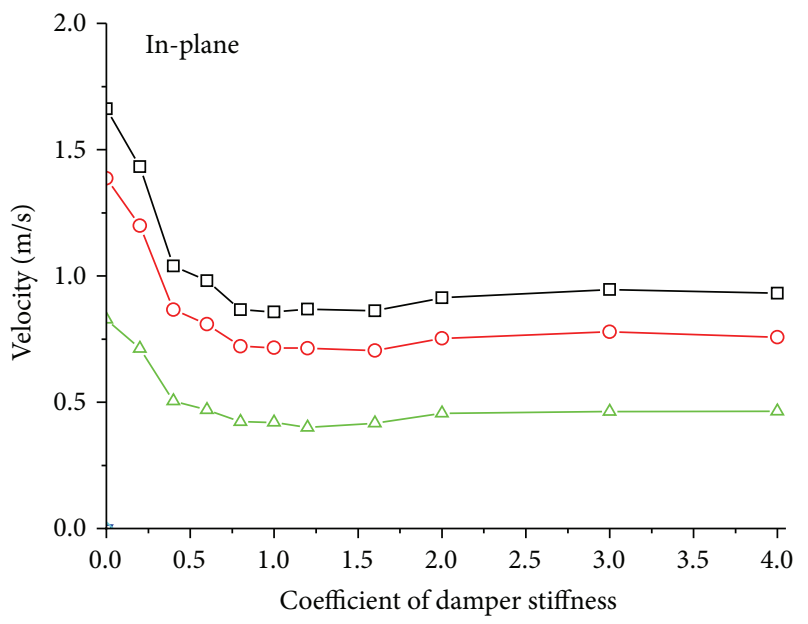

(c)

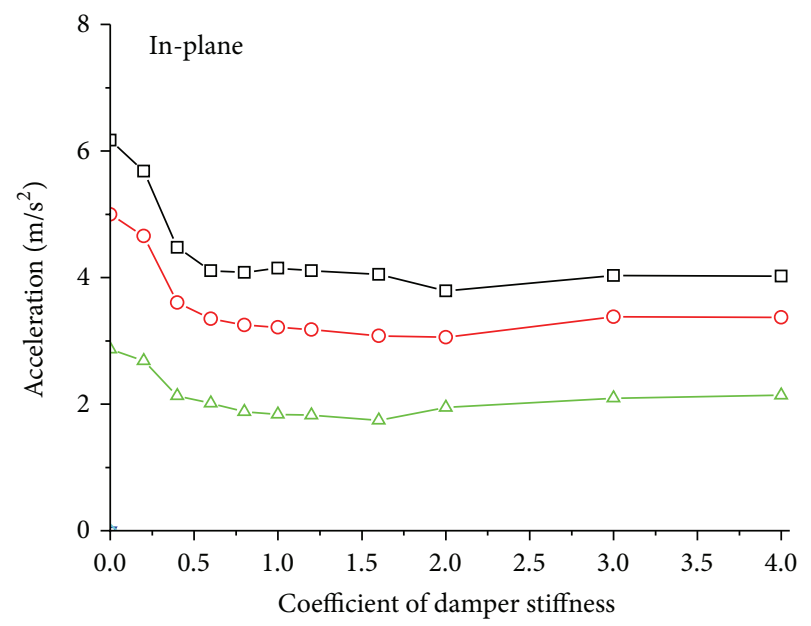

- - - Mass number 9 (top)

- - - Mass number 8 (crossarm)

$-\triangle-$ Mass number 6

(e)

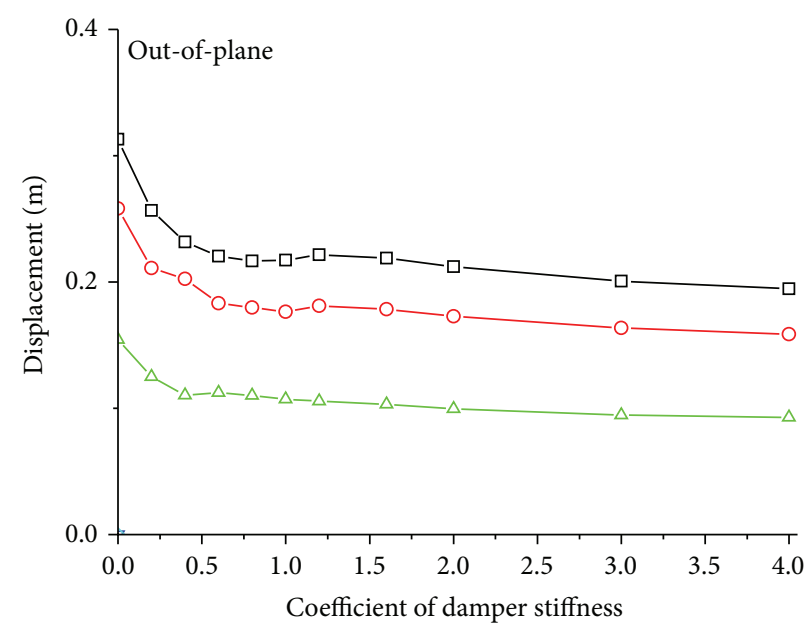

(b)

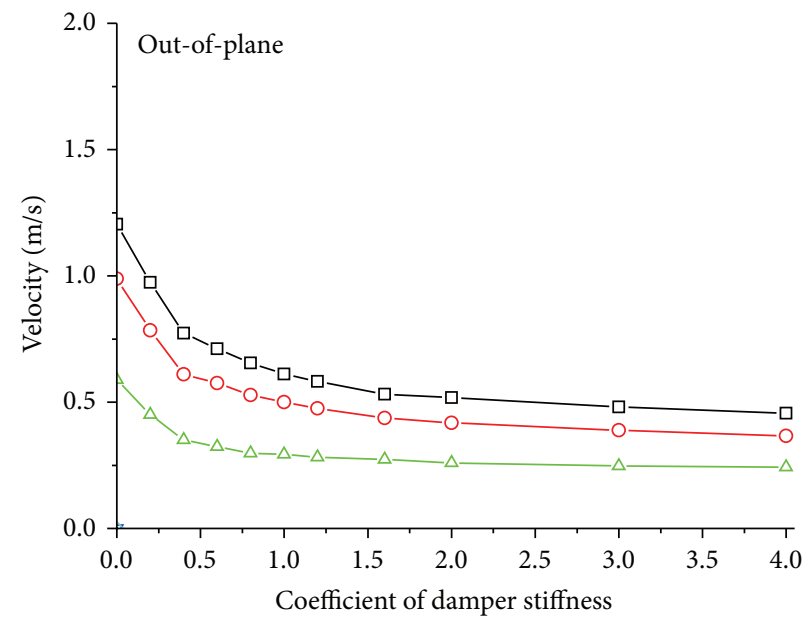

(d)

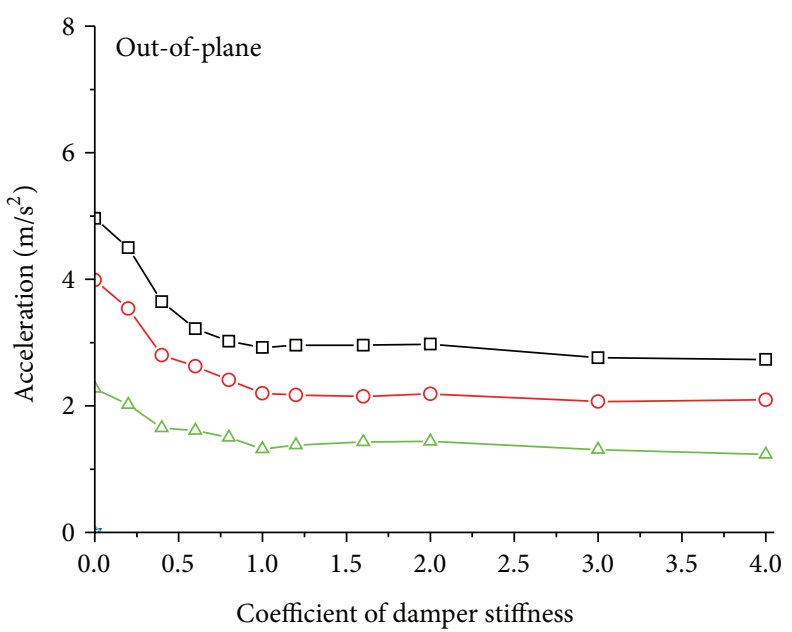

- - Mass number 9 (top)

- - - Mass number 8 (crossarm)

$-\Delta-$ Mass number 6

FIGURE 9: Variation of maximum responses with damper stiffness. 


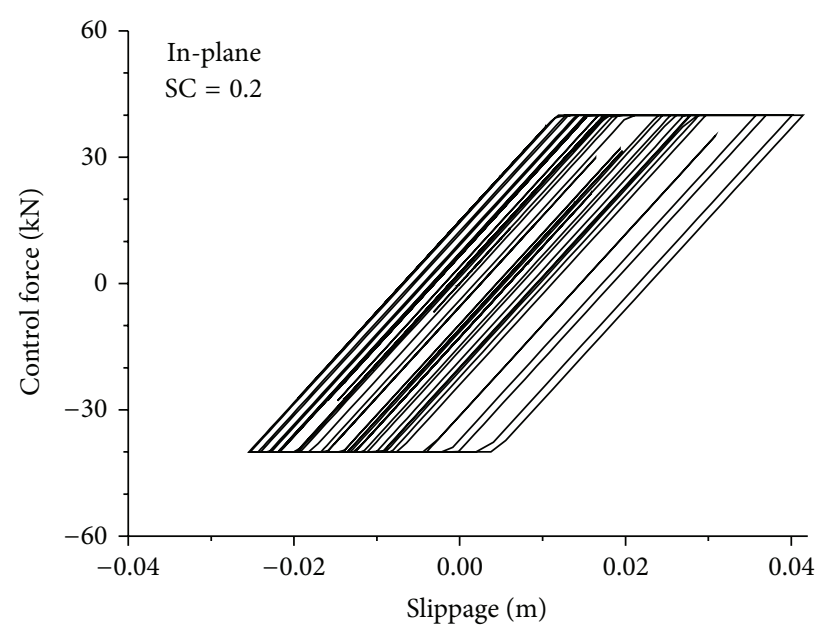

(a)

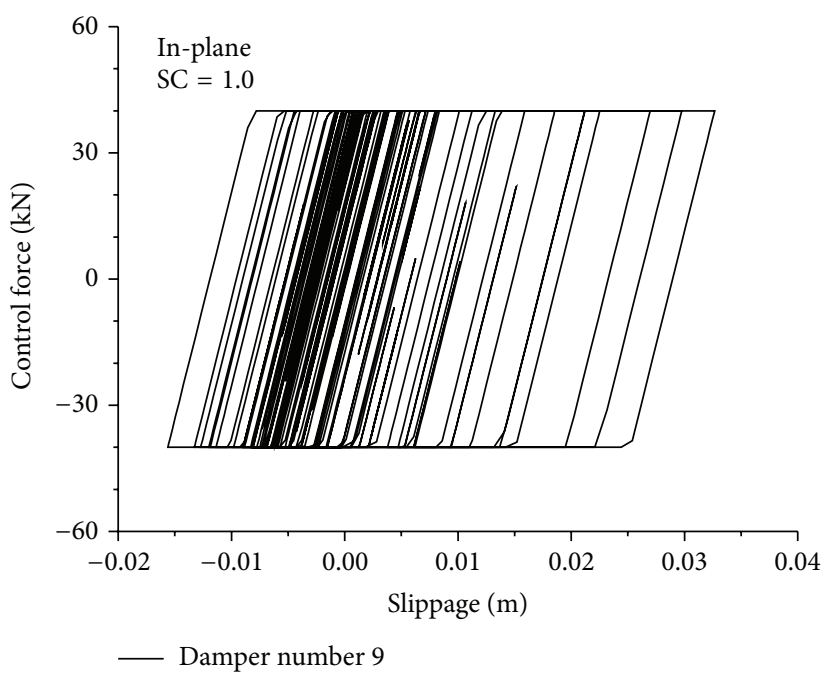

(c)

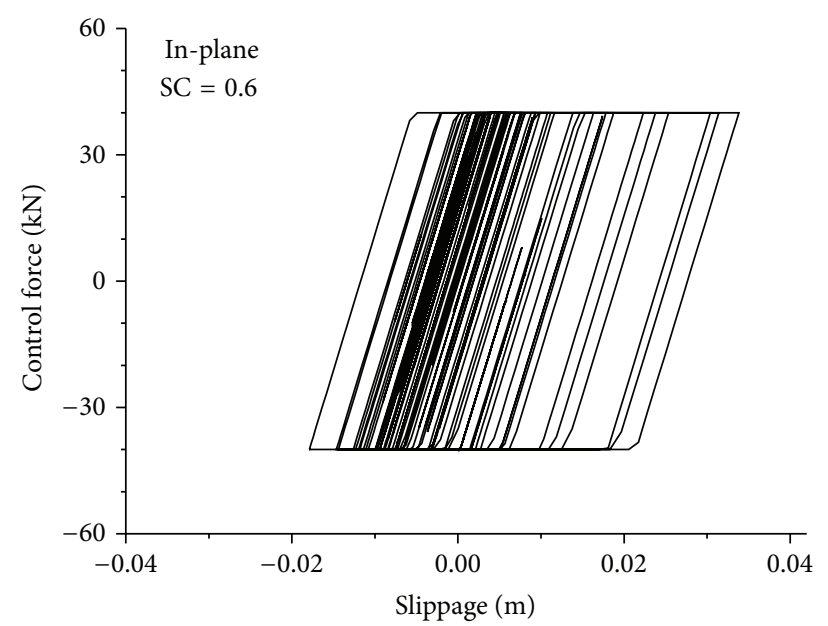

(b)

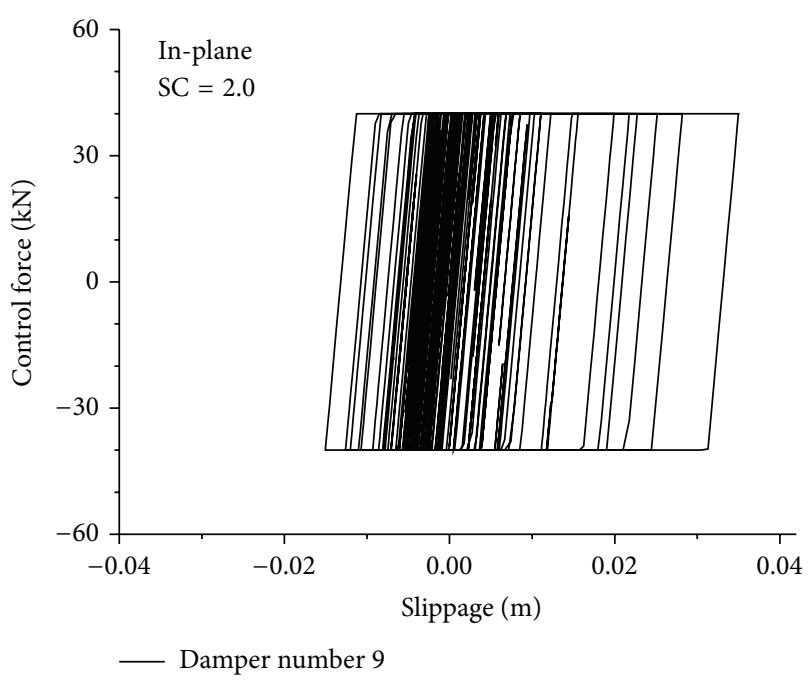

(d)

FIGURE 10: Hysteresis loops of friction damper for the in-plane vibration.

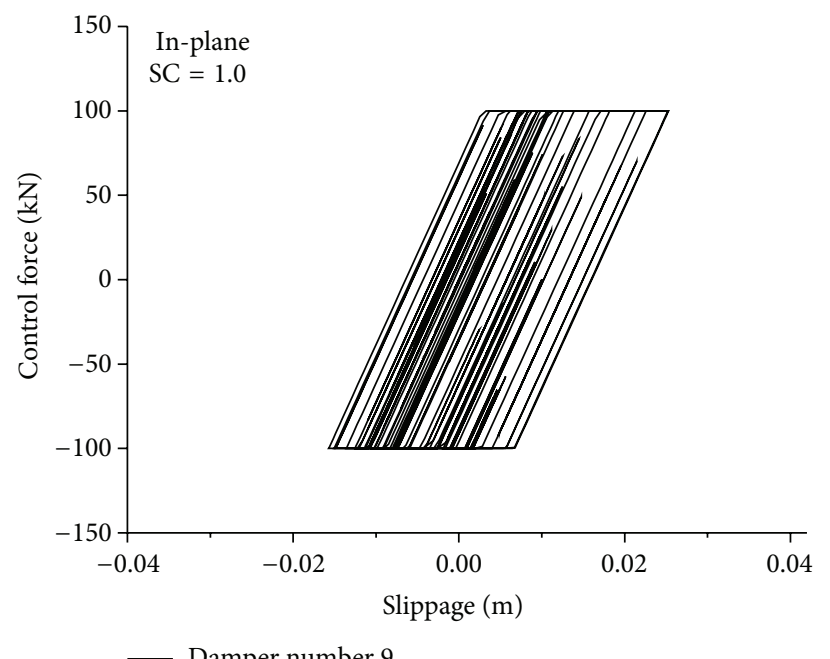

— Damper number 9

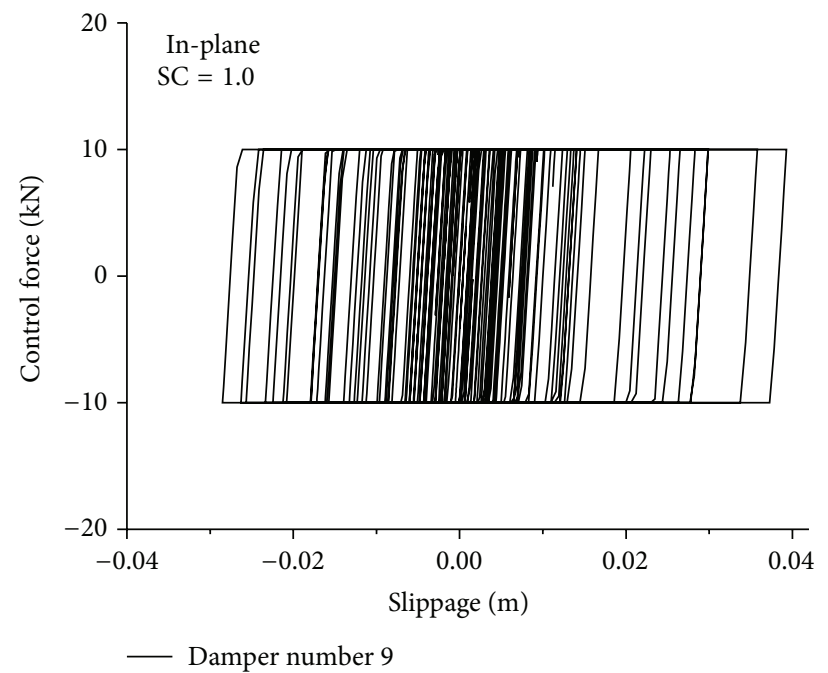

(b)

FIGURE 11: Comparison on hysteresis loops of friction damper for the in-plane vibration. 
slipping forces. Therefore, the control performance cannot be substantially improved by merely increasing the slipping forces of the damper. The axial stiffness of the friction damper should be increased accordingly with the increasing damper slipping force. Similar observations can be made from the control evaluation for the out-of-plane vibration which is not displayed due to page limitation. It can be concluded that the optimal axial stiffness of the friction damper is tightly related to the damper slipping force. A large value of the optimal axial stiffness is expected if the slipping force of the damper is large.

\section{Concluding Remarks}

The feasibility of using passive friction dampers to suppress the dynamic responses of a transmission tower-line system under wind excitations is performed in this study. A 2D lumped mass model of a transmission tower is developed for the dynamic analysis by simplifying the 3D FE model. The analytical model for the transmission tower-line system is developed by simulating the transmission line as several lumped masses connected with elastic elements. The mechanical model of the passive friction damper is presented by involving the effects of the damper axial stiffness. A real transmission tower-line system is taken as the example to investigate the efficacy of the proposed control approach through the detailed parametric study.

The made observations demonstrate that the installation of the friction dampers can substantially suppress the windinduced vibration of the transmission tower-line system for both the in-plane and out-of-plane vibration, respectively, because of its satisfactory energy-dissipating capacity. It is seen that no matter which tower mass is selected, there is an optimal value of control forces by which the best performance of the friction damper can be achieved. If the damper control force is increased after reaching the optimal value, the damper performance will deteriorate gradually. The dynamic responses for both the in-plane and out-ofplane vibration can be reduced rapidly when the stiffness coefficient of dampers increases from zero to the optimal axial stiffness value. Further increase in damper stiffness cannot substantially improve the control performance and leads to unnecessary cost increases. The optimal axial stiffness of the friction damper is tightly related to the damper slipping force.

\section{Conflict of Interests}

The authors declare that there is no conflict of interests regarding the publication of this paper.

\section{Acknowledgments}

The authors are grateful for the financial support from the National Natural Science Foundation of China (51178366), the technological project of the Chinese Southern Power Grid Co. Ltd. (K-GD2013-0783), the Fok Ying-Tong Education Foundation (131072), and the Natural Science Foundation of Hubei Province (2014CFA026).

\section{References}

[1] B. Chen, J. Zheng, and W. Qu, "Control of wind-induced response of transmission tower-line system by using magnetorheological dampers," International Journal of Structural Stability and Dynamics, vol. 9, no. 4, pp. 661-685, 2009.

[2] H.-F. Bai, T.-H. Yi, H.-N. Li, and L. Ren, "Multisensors on-site monitoring and characteristic analysis of UHV transmission tower," International Journal of Distributed Sensor Networks, vol. 2012, Article ID 545148, 10 pages, 2012.

[3] E. Simiu and R. Scanlan, Wind Effects on Structures, John Wiley and Sons, New York, NY, USA, 3rd edition, 1996.

[4] Q. Xie and L. Sun, "Failure mechanism and retrofitting strategy of transmission tower structures under ice load," Journal of Constructional Steel Research, vol. 74, pp. 26-36, 2012.

[5] E. Savory, G. A. R. Parke, M. Zeinoddini, N. Toy, and P. Disney, "Modelling of tornado and microburst-induced wind loading and failure of a lattice transmission tower," Engineering Structures, vol. 23, no. 4, pp. 365-375, 2001.

[6] R. C. Battista, R. S. Rodrigues, and M. S. Pfeil, "Dynamic behavior and stability of transmission line towers under wind forces," Journal of Wind Engineering and Industrial Aerodynamics, vol. 91, no. 8, pp. 1051-1067, 2003.

[7] H.-N. Li, S.-Y. Tang, and T.-H. Yi, "Wind-rain-induced vibration test and analytical method of high-voltage transmission tower," Structural Engineering and Mechanics, vol. 48, no. 4, pp. 435-453, 2013.

[8] P. S. Lee and G. McClure, "Elastoplastic large deformation analysis of a lattice steel tower structure and comparison with full-scale tests," Journal of Constructional Steel Research, vol. 63, no. 5, pp. 709-717, 2007.

[9] T. Okamura, T. Ohkuma, E. Hongo, and H. Okada, "Wind response analysis of a transmission tower in a mountainous area, Journal of Wind Engineering and Industrial Aerodynamics, vol. 91, no. 1-2, pp. 53-63, 2003.

[10] G. W. Housner, L. A. Bergman, T. K. Caughey et al., "Structural control: past, present, and future," Journal of Engineering Mechanics, vol. 123, no. 9, pp. 897-971, 1997.

[11] S. Ozono and J. Maeda, "In-plane dynamic interaction between a tower and conductors at lower frequencies," Engineering Structures, vol. 14, no. 4, pp. 210-216, 1992.

[12] H. Verma and P. Hagedorn, "Wind induced vibrations of long electrical overhead transmission line spans: a modified approach," Wind and Structures, vol. 8, no. 2, pp. 89-106, 2005.

[13] B. Chen, J. Zheng, and W. L. Qu, "Practical method for windresistant design of transmission tower-line system by using viscoelastic dampers," in Proceedings of the 2nd International Conference on Structural Condition Assessment, Monitoring and Improvement, pp. 1028-1034, Changsha, China, 2007.

[14] B. Chen, Y. L. Xu, and W. L. Qu, "Evaluation of atmospheric corrosion damage to steel space structures in coastal areas," International Journal of Solids and Structures, vol. 42, no. 16-17, pp. 4673-4694, 2005.

[15] M. Kleiber and T. D. Hien, The Stochastic Finite Element Method: Basic Perturbation Technique and Computer Implementation, John Wiley \& Sons, New York, NY, USA, 1992.

[16] K. J. Bathe, Finite Element Procedures, Prentice-Hall, New Jersey, NJ, USA, 1996.

[17] H. M. Irvine, Cable Structure, The MIT Press, New York, NY, USA, 1981. 
[18] L. Kempner Jr. and S. Smith, "Cross-rope transmission towerline dynamic analysis," Journal of Structural Engineering ASCE, vol. 110, no. 6, pp. 1321-1335, 1984.

[19] B. Chen, W. H. Guo, P. Y. Li, and W. P. Xie, "Dynamic responses and vibration control of the transmission tower-line system: a state-of-the-art review," The Scientific World Journal, vol. 2014, Article ID 538457, 20 pages, 2014.

[20] A. S. Pall and C. Marsh, "Response of friction damped braced frames," Journal of the Structural Division, vol. 108, no. 6, pp. 1313-1323, 1982.

[21] D. K. Nims, P. J. Richter, and R. E. Bachman, "The use of the energy dissipating restraint for seismic hazard mitigation," Earthquake Spectra, vol. 9, no. 3, pp. 467-489, 1993.

[22] Y. L. Xu and B. Chen, "Integrated vibration control and health monitoring of building structures using semi-active friction dampers. Part I-methodology," Engineering Structures, vol. 30, no. 7, pp. 1789-1801, 2008.

[23] B. Chen and Y. L. Xu, "Integrated vibration control and health monitoring of building structures using semi-active friction dampers. Part II. Numerical investigation," Engineering Structures, vol. 30, no. 3, pp. 573-587, 2008.

[24] M. Shinozuka and G. Deodatis, "Simulation of stochastic processes by spectral representation," Applied Mechanics Reviews, vol. 44, no. 4, pp. 191-204, 1991. 

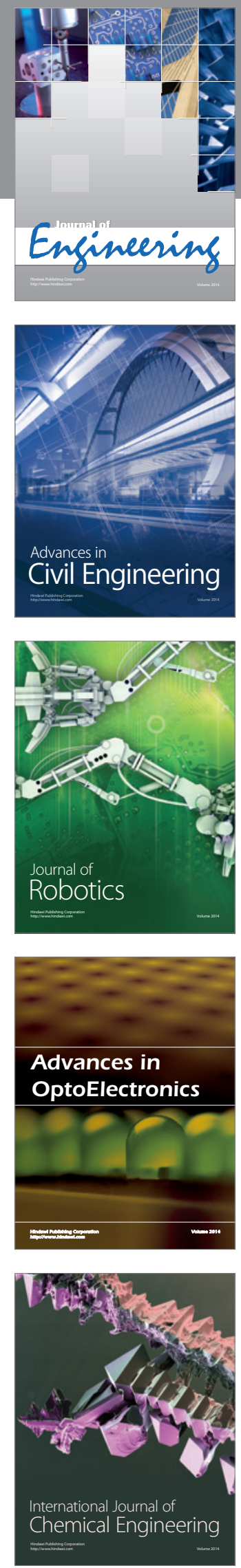

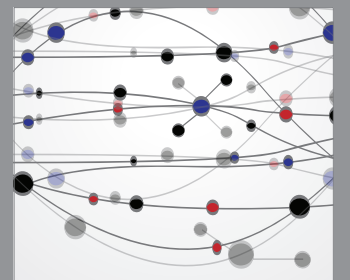

The Scientific World Journal
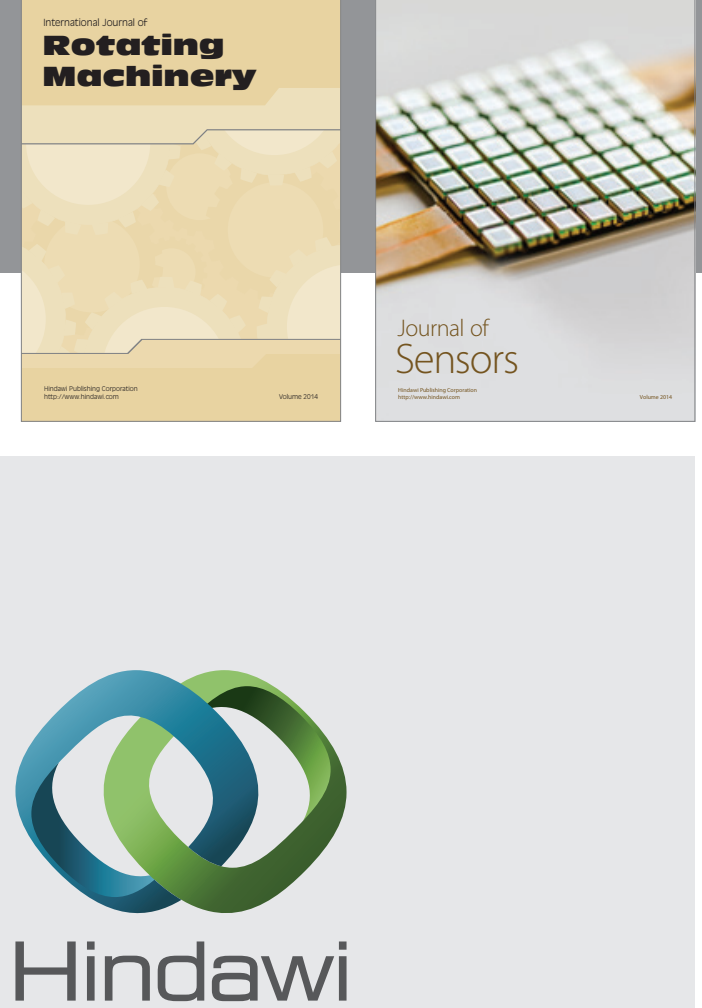

Submit your manuscripts at http://www.hindawi.com
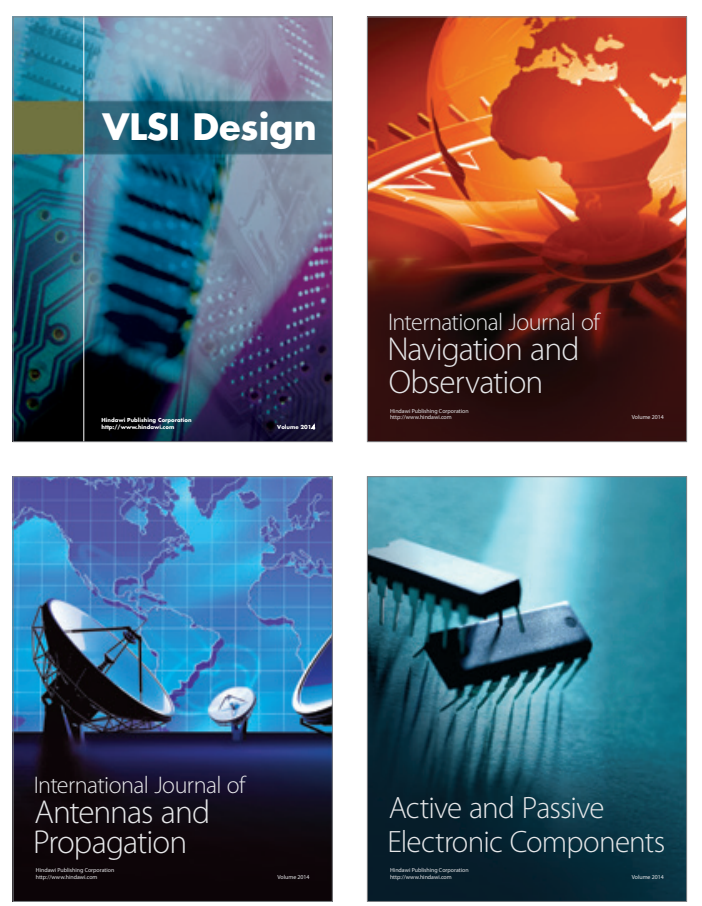
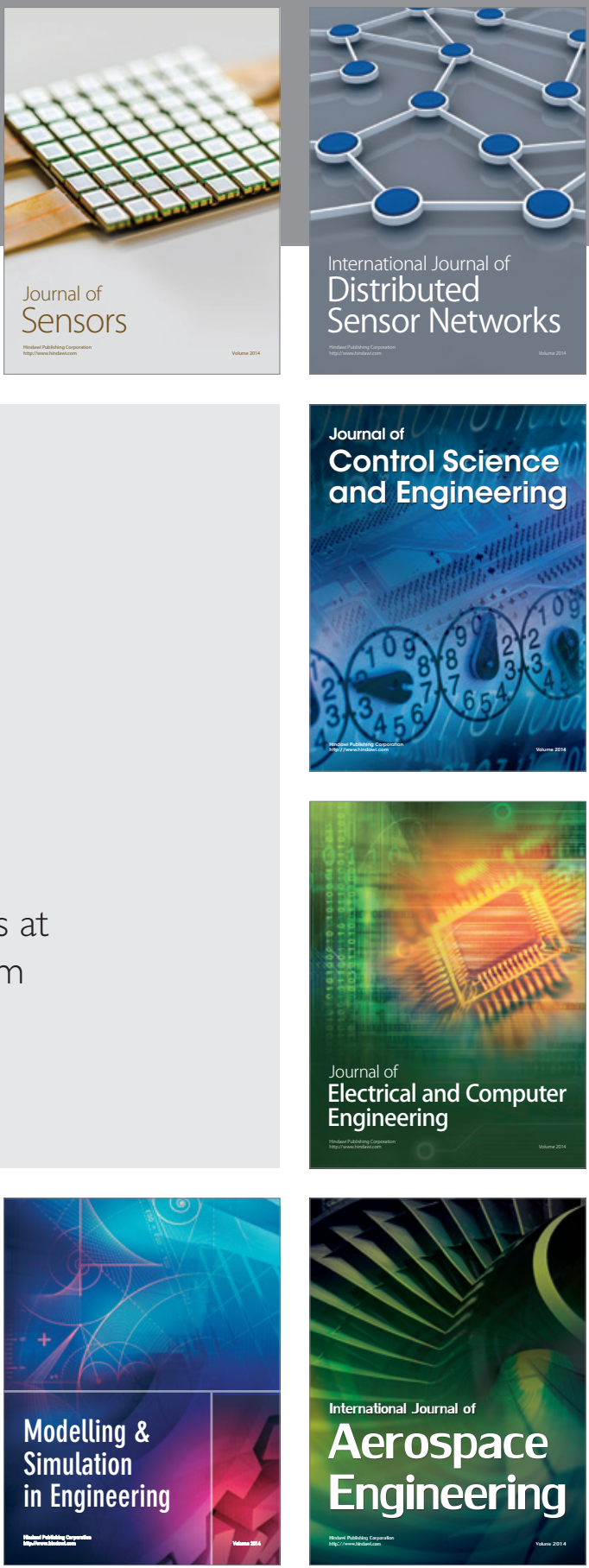

Journal of

Control Science

and Engineering
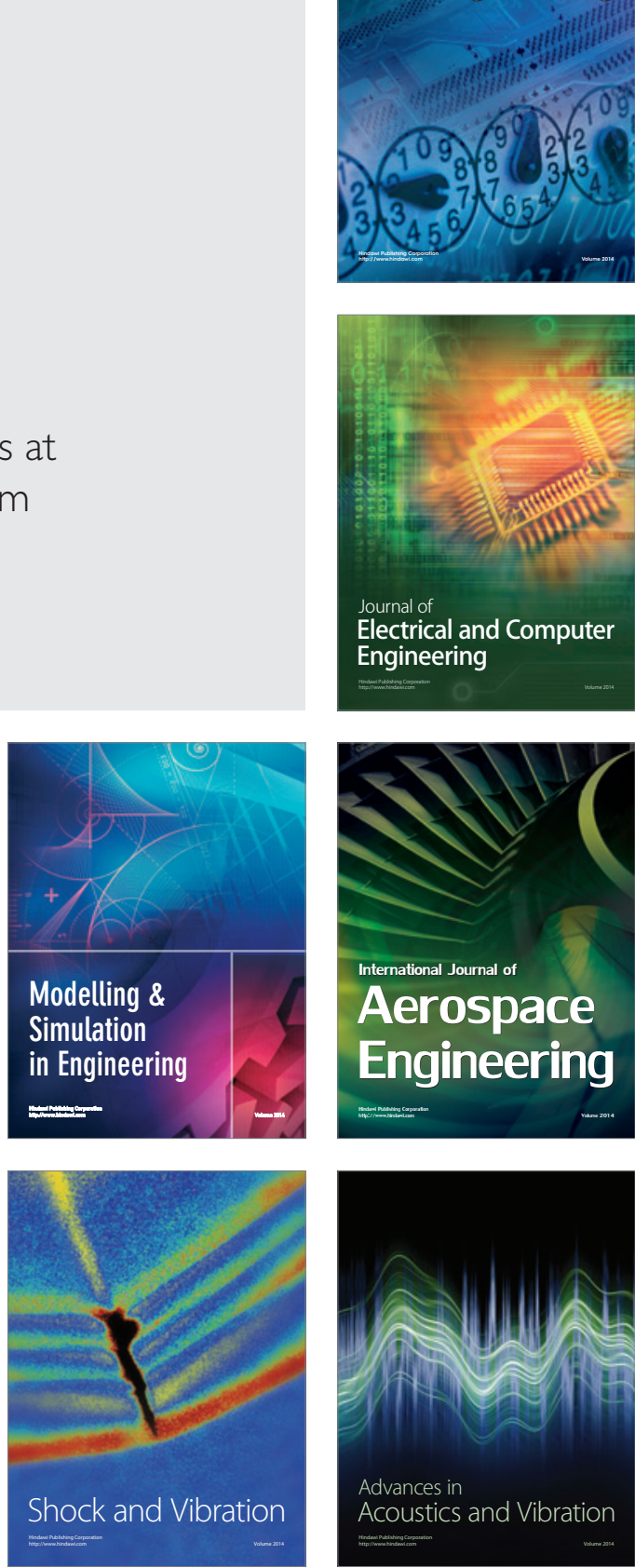